\title{
Endogenous prostaglandins in peptic ulcer disease
}

\author{
R. BAKER ${ }^{1}$, B. M. JAFFE, AND C. W. VENABLES
}

From the Department of Surgery, University of Newcastle upon Tyne, and Washington University School of Medicine, St Louis, Missouri, USA

SUMMARY Plasma concentrations of prostaglandins $\mathrm{E}$ and $\mathrm{F}$ have been measured by radioimmunoassay in patients undergoing diagnostic upper intestinal endoscopy. The results fail to support a previously reported deficiency of plasma PGE in duodenal ulcer patients. Plasma prostaglandin concentrations failed to correlate with the parameters of gastric secretion studied; and were unaffected by histamine $\mathrm{H}_{2}$-receptor blockade or the activity of duodenal ulceration. During combined pentagastrin and insulin secretory studies there was a significant corrrelation between the outputs of PGE and acid into gastric juice.

Prostaglandins of the E series are synthesised by the gastric mucosa and secreted into the gastric juice of man (Bennett et al., 1973; Cheung et al., 1976) and other mammalian species (Bennett et al., 1967; Baker et al., 1977a). Both natural E-type prostaglandins and their synthetic analogues have been shown to inhibit basal and stimulated gastric acid secretion in man, Rhesus monkey, dog, rat, and cat (Carter et al., 1973; Dajani et al., 1975; Wilson et al., 1975; Dajani and Callison, 1976; Robert et al., 1976; Konturek et al., 1976; Baker et al., 1978a); and to inhibit pepsin secretion in man, dog, and cat (Nezamis et al., 1971; Salmon et al., 1975; Konturek et al., 1976; Baker et al., 1978a). Accordingly it has been postulated that PGE may have a physiological role in the control of gastric secretion, perhaps by means of a negative feedback mechanism (Horton, 1969). We have recently demonstrated in animal studies a positive correlation between the gastric output of immunoreactive prostaglandins $E$ and $F$ and gastric acid secretion stimulated by pentagastrin and insulin (Baker et al., 1978b). A weaker correlation existed between the gastric outputs of these prostaglandins and pepsin secretion. However, prostaglandin $\mathrm{F}$ compounds are secreted in smaller quantities than PGE and have been reported as either not inhibiting gastric secretion (Robert et al., 1967) or having a weak or transitory effect (Newman et al., 1975; Baker et al., 1978a).

\footnotetext{
${ }^{1}$ Address for correspondence: R. Baker, Department of Surgery, University of Newcastle upon Tyne, Royal Victoria Infirmary, Newcastle upon Tyne, NE1 4LP.
}

Received for publication 13 November 1978
Administration of PGE has been shown to prevent the formation of gastroduodenal ulcers in several animal models (Robert et al., 1971; 1976; Lee et al., 1973) and has been used to treat peptic ulcers in man (Fung et al., 1974; Fung and Karim, 1976; Gibinski et al., 1977). Hinsdale et al. (1974) have reported that duodenal ulcer patients have lower concentrations of PGE in their plasma and basal gastric juice than have normal controls, and it has been suggested that prostaglandin deficiency may be an important aetiological factor in peptic ulcer disease (Robert, 1975). However, other workers studying duodenal ulcer patients have failed to confirm this PGE deficiency in either basal (Tonnesen et al., 1974) or insulin-stimulated (Cheung et al., 1976) gastric juice, but have noted a disruption of rhythms of basal PGE and acid secretion.

This study has been performed further to evaluate the role of endogenous prostaglandins in peptic ulcer disease.

\section{Methods}

One-hundred-and-fifty-nine patients, endoscoped for evaluation of upper gastrointestinal symptoms, were studied. All patients were fasted for at least 12 hours before endoscopy, which was performed by experienced endoscopists using both endand side-viewing instruments as indicated. On the basis of the endoscopic findings the patients were divided into four groups: (1) non-ulcer; (2) inactive duodenal ulcer (definite scarring of the duodenal cap or a previously endoscopically visualised duodenal ulcer); (3) active duodenal ulcer; and (4) active gastric ulcer. Patients with other known 394 
Table 1 Patient data: age, sex, and endoscopic diagnosis

\begin{tabular}{lllllr}
\hline Endoscopic diagnosis & No. & \multicolumn{2}{l}{ Mean age } & Male & Female \\
\cline { 2 - 5 } & & Years & Range & \\
\hline Non-ulcer & 64 & 40 & $16-78$ & 35 & 29 \\
Inactive duodenal ulcer & 19 & 40 & $20-69$ & 12 & 7 \\
Active duodenal ulcer & 57 & 42 & $16-70$ & 40 & 17 \\
Active gastric ulcer & 19 & 58 & $39-77$ & 11 & 8 \\
\hline
\end{tabular}

diseases, a history of gastrointestinal surgery or of recent ingestion of known prostaglandin synthetase inhibitors or steroids were excluded from the series. Data on patients are summarised in Table 1. Immediately before administration of sedation for endoscopy $5 \mathrm{ml}$ specimens of blood were obtained by antecubital venepuncture (between 1400 and 1600 hours), collected into heparinised tubes, centrifuged at $4^{\circ} \mathrm{C}$, and the plasma obtained stored at $-20^{\circ} \mathrm{C}$ until extraction and estimation of radioimmunoassayable prostaglandins.

Plasma prostaglandins were measured in 21 patients with active duodenal ulceration before and after 28 days' treatment with the histamine $\mathbf{H}_{2}$ receptor antagonist cimetidine (1.6 g/day). All patients were endoscoped immediately before and after treatment and blood samples were collected at the time of this procedure.

Fasting serum gastrin determinations (Blair et al., 1975) were obtained in 13 patients with active duodenal ulceration.

Gastric secretory studies were performed in 14 patients with active duodenal ulceration. After an overnight fast and the withholding of all medications for 24 hours, a double-lumen nasogastric tube was passed into the stomach and its satisfactory position confirmed by the recovery of a known amount of injected fluid. A 'wash-out' technique employing phenol red as marker was used to estimate the amount of secretion escaping collection (Venables, 1972). Resting gastric secretion was aspirated and discarded. After a preliminary wash-out period of at least 15 minutes basal secretion was collected over an additional 15 minute period. In seven patients, after the basal collection, pentagastrin (Peptavlon, ICI, England) $6 \mu \mathrm{g} \mathrm{kg}^{-1}$ was given by intramuscular injection and the stimulated secretion collected over the next 60 minutes. At the end of this period soluble insulin (Wellcome, England) $0.2 \mu \mathrm{kg}^{-1}$ was given intravenously and secretion collected for another 75 minutes. Blood glucose estimations performed on samples obtained immediately before and $\mathbf{4 5}$ minutes after the insulin injection confirmed an adequate hypoglycaemic response, mean preand post-insulin blood glucose levels being 4.3 and $1.2 \mathrm{mmol}^{-1}$ respectively. Plasma samples were obtained for prostaglandin estimation in the fasting state (before nasogastric intubation), one hour after the pentagastrin injection, and $\mathbf{4 5}$ minutes after the insulin injection. Acid output was determined by electrometric titration of $1 \mathrm{ml}$ samples of gastric juice to $\mathrm{pH} 7.0$ with $0.1 \mathrm{~m} \mathrm{NaOH}$ (Radiometer, Denmark) and expressed as $\mathrm{mmol} \mathrm{H}^{+} \mathrm{h}^{-1}$. Pepsin activity was determined by a haemoglobin digestion method (Chiang et al., 1966) and expressed as milligram equivalents to bovine pepsin $\mathrm{h}^{-1}$. In five patients samples of the collected gastric juice were stored at $-20^{\circ} \mathrm{C}$ until extraction and estimation of prostaglandin by radioimmunoassay. Prostaglandin output into gastric juice was expressed as ng 15 min $^{-1}$.

\section{PROSTAGLANDIN EXTRACTION AND}

\section{RADIOIMMUNOASSAY}

One millilitre samples of plasma and gastric juice were extracted by the addition of $3.0 \mathrm{ml}$ of an organic solvent solution (ethyl acetate: isopropanol: $0 \cdot 1 \mathrm{~m}-\mathrm{HCl}, 3: 3: 1)$ and two phases created by the addition of $2.0 \mathrm{ml}$ ethylacetate and $3.0 \mathrm{ml}$ water. The organic phases were aspirated, evaporated at $37^{\circ} \mathrm{C}$, and dissolved in benzene: ethyl acetate: methanol, 60:40:2. Fractions containing prostaglandins of the $E$ and $F$ groups were eluted separately from microsilicic acid columns by increasing concentrations of methanol ( $2 \%$ for PGEs and $17 \%$ for PGFs respectively) (Jaffe and Parker, 1972). Concentrations of immunoreactive PGE and PGF were measured using specific homologous radioimmunoassay systems (Jaffe et al., 1973). Antibodies to PGE were raised in rabbits immunised with $\mathrm{PGE}_{1}$ conjugated to Keyhole Limpet haemocyanin using ethyl chloroformate (Jaffe et al., 1971); antibodies to $\mathrm{PGF}_{2 \alpha}$ were elicited in rabbits immunised with PGF $_{2 \alpha}$ conjugated to bovine serum albumin using a water-soluble carbodiimide (Jaffe et al., 1971). Tritiated markers $\left(\left[{ }^{3} \mathrm{H}\right] \mathrm{PGE}_{1}\right.$ and $\left.\left[{ }^{3} \mathrm{H}\right] \mathrm{PGF}_{2 \alpha}\right)$ were purchased from the New England Nuclear Company and stored at $-20^{\circ} \mathrm{C}$ under nitrogen until they were used. Separation of antibody-bound and free labelled ligand was performed using dextrancoated charcoal. By this method, separation of PGEs and PGFs from each other, and from PGAs, PGBs, and thromboxane $\mathrm{B}_{2}$, is $>99 \%$. The sensitivity of each radioimmunoassay is $5 \mathrm{pg} \mathrm{ml}^{-1}$. Intra- and interassay coefficients of variation are consistently less than $10 \%$.

Mean results for each group were compared and the significance of differences tested by Student's $t$ test for paired or unpaired data as appropriate, where significant differences between the variances of the groups occurred Cochrane's correction factor was applied. Possible correlations were tested by the 
Table 2 Plasma prostaglandin concentrations ( $\mathrm{pg} \mathrm{ml}^{-1}$ ) in dyspeptic patients $(\bar{x} \pm 1$ SEM $)$

\begin{tabular}{lcccc}
\hline $\begin{array}{c}\text { Non-ulcer } \\
(n=64)\end{array}$ & $\begin{array}{l}\text { Inactive DU } \\
(n=19)\end{array}$ & $\begin{array}{c}\text { Active DU } \\
(n=57)\end{array}$ & $\begin{array}{c}\text { Active GU } \\
(n=19)\end{array}$ \\
\hline PGE & $233 \pm 17$ & $272 \pm 48$ & $283 \pm 21$ & $276 \pm 47$ \\
PGF & $59 \pm 5$ & $75 \pm 12$ & $57 \pm 6$ & $66 \pm 19$ \\
\hline
\end{tabular}

Table 3 Plasma prostaglandin concentrations ( $p g \mathrm{ml}^{-1}$ ) in cimetidine treated patients $(\bar{x} \pm 1$ SEM)

\begin{tabular}{llllll}
\hline & \multicolumn{2}{l}{ Ulcer healed $(n=18)$} & & \multicolumn{2}{l}{ Ulcer unhealed $(n=3)$} \\
\cline { 2 - 3 } & $P G E$ & $P G F$ & & $P G E$ & $P G F$ \\
\hline Pre-treatment & $215 \pm 21$ & $42 \pm 9$ & & $240 \pm 55$ & $24 \pm 5$ \\
Post-treatment & $257 \pm 25$ & $35 \pm 3$ & & $275 \pm 59$ & $28 \pm 9$ \\
\hline
\end{tabular}

method of least squares ( $r=$ correlation coefficient) and the Spearmann rank test. Significance was set at $\mathbf{P}<0.05$.

\section{Results}

The age distributions of the patient groups were similar with the exception of the gastric ulcer group, which was significantly older (Table 1 ). There were wide variations in individual plasma PGE and PGF concentrations within all the groups, but no significant difference between any of the groups (Table 2). There was no correlation between age and plasma PG, or between sex and plasma PG, irrespective of the endoscopic diagnosis, or within any of the diagnostic groups.

As determined endoscopically 18 of the 21 patients treated with cimetidine obtained duodenal ulcer healing. Mean fasting plasma levels of PGE and PGF did not alter significantly during the course of therapy (Table 3).

Fasting serum immunoreactive gastrin concentrations measured in 13 active duodenal ulcer patients were all within the normal range (mean \pm $\mathrm{SEM}=52 \pm 6 \mathrm{pg} \mathrm{ml}^{-1}$ ) and showed no correlation with plasma concentrations of PGE or PGF (Fig. 1).

In 14 duodenal ulcer patients the mean basal gastric outputs of acid and pepsin were $13 \pm 2 \mathrm{mmol}$ $\mathrm{h}^{-1}$ and $221 \pm 33 \mathrm{mg} \mathrm{h}^{-1}(\mathrm{X} \pm \mathrm{SEM})$ respectively. Mean fasting plasma concentrations of PGE and PGF were $200 \pm 32$ and $62 \pm 13 \mathrm{pg} \mathrm{ml}^{-1}$ respectively. There was no correlation between fasting plasma prostaglandin concentration and basal acid or pepsin concentrations or outputs.

In seven patients plasma concentrations of PGE and PGF obtained during stimulation with pentagastrin and insulin did not correlate with either acid (Figs. 2 and 3) or pepsin output at that time.

Concentrations of PGE and PGF were measured in the gastric juice of five patients undergoing combined pentagastrin and insulin secretory studies (Fig. 4). There was a significant positive correlation between the gastric output of PGE (pg $15 \mathrm{~min}^{-1}$ ) and that of acid (mmol $\left.15 \mathrm{~min}^{-1}\right) \quad(r=0.563)$ (Fig. 5), but no correlation between the outputs of PGE and pepsin. The output of PGF correlated with neither acid nor pepsin output.

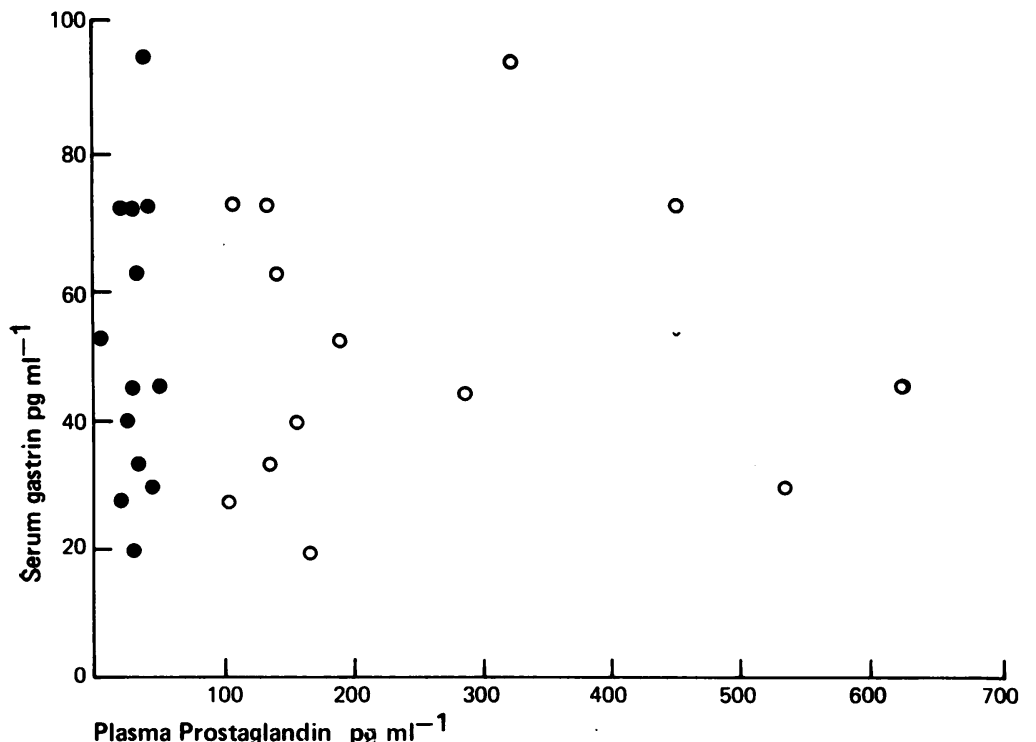

Fig. 1 The relationship between serum gastrin concentrations and plasma concentrations of PGE $(O)$ and $P G F(O)$ in 13 duodenal ulcer patients. 


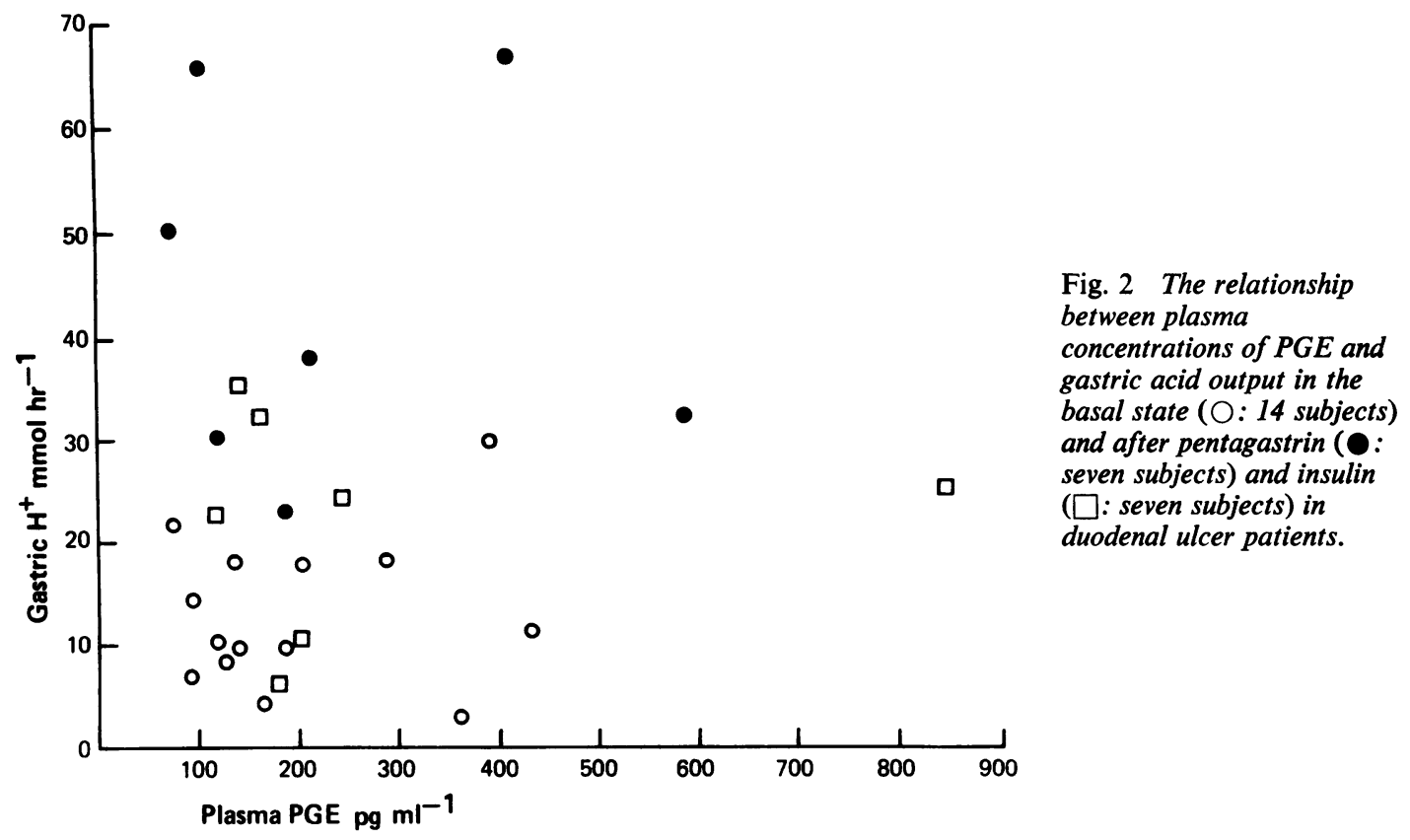

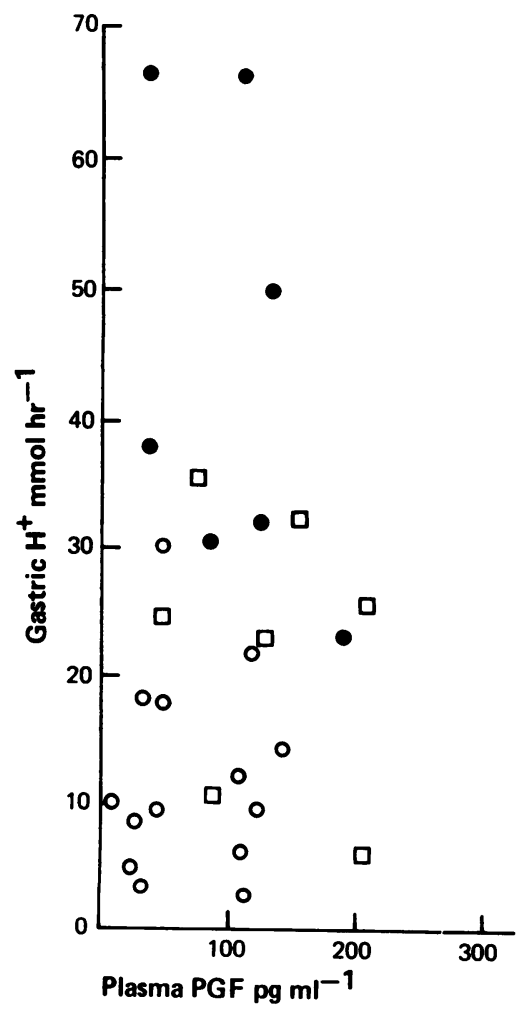

Fig. 3 The relationship between plasma concentrations of PGF and gastric acid output in the basal state $(O$ : 14 subjects) and after pentagastrin ( $O$ : seven subjects) and insulin ( $\square$ : seven subjects) in duodenal ulcer patients.

\section{Discussion}

These results show that plasma PGE concentrations in duodenal ulcer patients are not lower than normal as previously suggested by Hinsdale and his colleagues (1974), or higher than normal as suggested by our preliminary results (Baker et al., 1977b). Plasma prostaglandins do not appear to be related to gastric secretory status, serum gastrin concentration, or a specific diagnosis in dyspeptic patients. Furthermore, plasma prostaglandin concentrations are unaltered by histamine $\mathbf{H}_{2}$-receptor blockade or the activity of duodenal ulceration.

Although prostaglandins are relatively stable in blood (Ferreira and Vane, 1967), their rapid clearance from the circulation, up to $95 \%$ in a single passage through the lungs and liver (Ferreira and Vane, 1967; Piper et al., 1970; Hammond et al., 1977), makes it unlikely that changes in gastric prostaglandin metabolism will be reflected in the plasma or that plasma prostaglandin levels will influence gastric secretory status (with the exception of relatively large prostaglandin infusions).

As prostaglandins are synthesised and can be inactivated within the same tissues (Pace-Asciak and Wolfe 1970; Pace-Asciak, 1972; Peskar and Peskar 1976), and are rapidly cleared from the circulation, it is likely that their action is a local one. Variations in the gastric output of prostaglandins occur under differing stimulatory conditions (Baker et al., 1978b, c) and it seems reasonable to assume that changes in gastric mucosal prostaglandin metabolism 

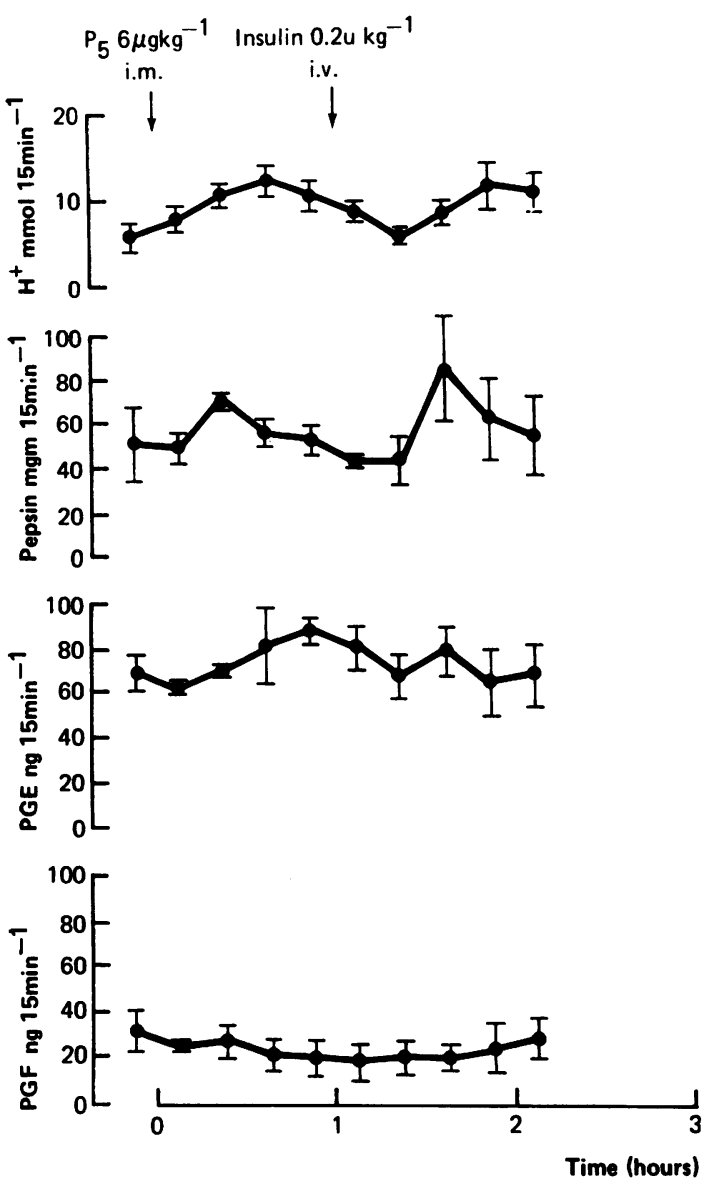

Fig. 4 The relationships between the gastric outputs of acid, pepsin, PGE, and PGF in the basal state and after pentagastrin and insulin stimulation in five duodenal ulcer patients. Responses are mean \pm 1 SEM.

will be paralleled by changes in the gastric juice. In the duodenal ulcer patients who were studied the output of PGE into gastric juice correlated significantly with gastric acid output. These results are compatible with the proposed role of locally produced PGE in the physiological control of gastric acid secretion. However, PGE output into gastric juice may be volume dependent and so provide a spurious correlation with $\mathrm{H}^{+}$output-indeed, animal studies suggest that this may well be the case (Baker et al., 1978c and unpublished data). Furthermore, although allowing of the hypothesis that gastric PGE output is related to gastric acid output, these results do not preclude some other role for PGE in gastric juice-for example, their cytoprotective effect (Robert et al., 1971).

More recently it has been demonstrated that

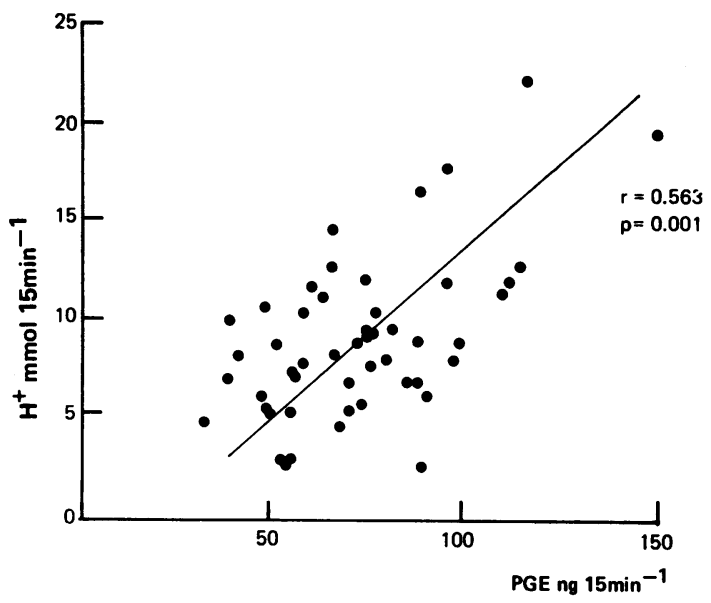

Fig. 5 The relationship between the gastric outputs of $P G E$ and acid during secretory function tests in five duodenal ulcer patients. The secretory data are illustrated in Fig. 4. $r=$ the correlation coefficient and $\mathrm{P}=$ the significance of the regression line.

prostacyclin is generated by the gastric mucosa and can inhibit gastric acid output (Whittle et al., 1978). Under certain experimental conditions prostacyclin is a more potent inhibitor of gastric secretion than is $\mathrm{PGE}_{2}$, but differences in the stability and pulmonary inactivation of these compounds make direct comparison difficult. Further evaluation of prostacyclin and its relationship to PGE is required before their relative roles can be assessed.

We thank Mrs I. M. Kenney, Mr L. Lavalle, Miss I. M. Robson and Mrs D. Wallace for excellent technical assistance. Serum gastrin estimations were performed by Dr D. J. Sanders, Department of Physiology, University of Newcastle upon Tyne. R. Baker was supported by a grant from the Scientific and Research Committee, Newcastle Area Health Authority (Teaching).

\section{References}

Baker, R., Jaffe, B. M., Labib, L. A., Reed, J. D., Shaw, B., and Venables, C. W. (1977a). Have prostaglandins a role in the control of secretion in the stomach? (Abstract.) British Journal of Surgery, 64, 295-296.

Baker, R., Jaffe, B. M., Reed, J. D., Shaw, B., and Venables, C. W. (1977b). Are prostaglandins deficient in peptic ulceration? (Abstract). Gut, 18, 950-951.

Baker, R., Jaffe, B. M., Reed, J. D., Shaw, B., and Venables, C. W. (1978a). Exogenous prostaglandins and gastric secretion in the cat. Journal of Physiology, 278, 441-450.

Baker, R., Jaffe, B. M., Reed, J. D., Shaw, B., and Venables, C. W. (1978b). Endogenous prostaglandins and gastric secretion in the cat. Journal of Physiology, 278, 451-460.

Baker, R., Jaffe, B. M., Reed, J. D., Shaw, B., and Venables, C. W. (1978c). Gastric prostaglandin output, and the 
effect of various secretory inhibitors, in the conscious cat (Abstract). British Journal of Surgery, 65, 820.

Blair, E. L., Grund, E. R., Reed, J. D., Sanders, D. J., Sanger, G., and Shaw, B., (1975). The effect of sympathetic nerve stimulation on serum gastrin, gastric acid secretion and mucosal blood flow responses to meat extract stimulation in anaesthetised cats. Journal of Physiology, 253, $493-504$.

Bennett, A., Friedmann, C. A., and Vane, J. R. (1967). Release of prostaglandin $\mathrm{E}_{1}$ from the rat stomach. Nature, 216, 873-876.

Bennett, A., Stamford, I. F., and Unger, W. G. (1973). Prostaglandin $E_{2}$ and gastric acid secretion in man. Journal of Physiology, 229, 349-360.

Carter, D. C., Karim, S. M. M., Bhana, D., and Ganesan, P. A. (1973). Inhibition of human gastric secretion by prostaglandin. British Journal of Surgery, 60, 828-831.

Cheung, L. Y., Jubiz, W., and Moore, J. G. (1976). Gastric prostaglandin $\mathrm{E}$ output during basal and stimulated acid secretion in normal subjects and patients with duodenal ulcer. Journal of Surgical Research, 20, 369-372.

Chiang, L., Sanchez-Chiang, L., Wolf, S., and Tang, J. (1966). The separate determination of human pepsin and gastricsin. Proceedings of the Society of Experimental Biology (Med.), 122, 700-704.

Dajani, E. Z., and Callison, D. A. (1976). Gastric antisecretory actions of (15 S)-15-methyl prostaglandin $E_{2}$ methyl ester and natural prostaglandin $E_{2}$ in Rhesus monkeys. Prostaglandins, 11, 799-808.

Dajani, E. Z., Driskill, D. R., Bianchi, R. G., and Collins, P. W. (1975). Comparative gastric antisecretory and antiulcer effects of prostaglandin $E_{1}$ and its methyl ester in animals. Prostaglandins, 10, 205-215.

Ferreira, S. H., and Vane, J. R. (1967). Prostaglandins: their disappearance from and release into the circulation. Nature, 216, 868-873.

Fung, W. P., and Karim, S. M. M. (1976). Effect of prostaglandin $\mathrm{E}_{2}$ on the healing of gastric ulcers: A double blind endoscopic trial. Australian and New Zealand Journal of Medicine, 6, 121-122.

Fung, W. P., Karim, S. M. M., and Tye, C. Y. (1974). Effect of 15 (R) 15-methylprostaglandin $E_{2}$ methyl ester on healing of gastric ulcers. Lancet, 2, 10-12.

Gibinski. K., Rybicka, J., Mikos, E., and Nowak, A. (1977). Double blind clinical trial on gastroduodenal ulcer healing with prostaglandin $\mathrm{E}_{2}$ analogues. Gut, 18, 636-639.

Hammond, G. L., Cronau, L. H., Whittaker, D., and Gillis, C. N. (1977). Fate of prostaglandins $E_{1}$ and $A_{1}$ in the human pulmonary circulation. Surgery, 81, 716-722.

Hinsdale, J. G., Engel, J. J., and Wilson, D. E. (1974). Prostaglandin E in peptic ulcer disease. Prostaglandins, 6, 459-500.

Horton, E. W. (1969). Hypotheses on physiological roles of prostaglandins. Physiological Reviews, 49, 122-161.

Jaffe, B. M., Behrman, H. R., and Parker, C. W. (1973). Radioimmunoassay measurement of prostaglandins E, A and $\mathrm{F}$ in human plasma. Journal of Clinical Investigation, 52, 398-405.

Jaffe, B. M., and Parker, C. W. (1972). Extraction of PGE from human serum for radioimmunoassay. In Third Conference on Prostaglandins in Fertility Control, pp. 169179. Edited by S. Bergström, K. Green, and B. Samuelsson. Karolinska Institutet: Stockholm.

Jaffe, B. M., Smith, J. W., Newton, W. T., and Parker, C. W. (1971). Radioimmunoassay for prostaglandins. Science,
N. Y., 171, 494-496.

Konturek, S. J., Radecki, T., and Pucher, A. (1976). Comparison of natural and synthetic prostaglandins on gastric and pancreatic secretions and peptic ulcer formation in conscious cats. Digestion, 14, 44-61.

Lee, Y. H., Cheng, W. D., Bianchi, R. G., Mollison, K., and Hansen, J. (1973). Effects of oral administration of $\mathrm{PGE}_{2}$ on gastric secretion and experimental peptic ulcerations. Prostaglandins, 3, 29-45.

Newman, A., De Moraes-Filho, J. P. P., Philippakos, D., and Misiewicz, J. J. (1975). The effect of intravenous infusions of prostaglandins $\mathrm{E}_{2}$ and $\mathrm{F}_{2} a$ on human gastric function. Gut, 16, 272-276.

Nezamis, J. E., Robert, A., and Stowe, D. F. (1971). Inhibition by prostaglandin $E_{1}$ of gastric secretion in the dog. Journal of Physiology, 218, 369-383.

Pace-Asciak, C. (1972). Prostaglandin synthetase activity in the rat stomach fundus. Activation by L-norepinephrine and related compounds. Biochimica et Biophysica Acta, 280, 161-171.

Pace-Asciak, C., and Wolfe, L. S. (1970). Biosynthesis of prostaglandins $E_{2}$ and $F_{2} a$ from tritium-labelled arachidonic acid by rat stomach homogenates. Biochimica et Biophysica Acta, 218, 539-542.

Peskar, B. M., and Peskar, B. A. (1976). On the metabolism of prostaglandins by human gastric fundus mucosa. Biochimica et Biophysica Acta, 424, 430-438.

Piper, P. J., Vane, J. R., and Wyllie, J. H. (1970). Inactivation of prostaglandins by the lungs. Nature, 225, 600-604.

Robert, A. (1975). The role of prostaglandins in the etiology and treatment of gastrointestinal diseases. Proceedings of the Sixth International Congress of Pharmacology, 5 , 161-173.

Robert, A., Nezamis, J. E., and Phillips, J. P. (1967). Inhibition of gastric secretion by prostaglandins. American Journal of Digestive Diseases, 12, 1073-1076.

Robert, A., Schultz, J. R., Nezamis, J. E., and Lancaster, C. (1976). Gastric antisecretory and antiulcer properties of $\mathrm{PGE}_{2}, 15-$ methyl $\mathrm{PGE}_{2}$, and 16, 16-dimethyl PGE $\mathrm{PG}_{2}$. Gastroenterology, $70,359-370$.

Robert, A.. Stowe, D. F., and Nezamis, J. E. (1971). Prevention of duodenal ulcers by administration of prostaglandin $\mathrm{E}_{2}\left(\mathrm{PGE}_{2}\right)$. Scandinavian Journal of Gastroenterology, 6, 303-305.

Salmon, J. A., Karim, S. M. M., Carter, D. C., Adaikan, P. G., and Bhana, D. (1975). Effect of 15 (R) 15-Methyl Prostaglandin $E_{2}$ methyl ester on basal and pentagastrin stimulated pepsin secretion in man. International Research Communications System, Medical Science, 3, 83.

Tonnesen, M. G., Jubiz, W., Moore, J. G., and Frailey, J. (1974). Circadian variation of prostaglandin E (PGE) production in human gastric juice. American Journal of Digestive Diseases, 19, 644-648.

Venables, C. W. (1972). An assessment of the value of measuring uncontrolled gastric secretion during routine secretion studies in man. British Journal of Surgery, 59, 473-477.

Whittle, B. J. R., Boughton-Smith, N. K., Moncada, S., and Vane, J. R. (1978). Actions of Prostacyclin (PGI and its product, 6-OXO-PGF ${ }_{1 \alpha}$ on the rat gastric mucosa in vivo and in vitro. Prostaglandins, 15, 955-967.

Wilson, D. E., Winnan, G., Quertermus, J., and Tao, P. (1975). Effects of an orally administered prostaglandin analogue $\left(16,16\right.$-Dimethyl prostaglandin $\left.E_{2}\right)$ on human gastric secretion. Gastroenterology, 69, 607-611. 